\title{
Relationship between Helicobacter pylori detection and an increased risk of infection in childhood
}

Venerando R (1, 2), Rasmussen LT (1, 3), de Labio RW (4), Gatti LL (2), Francisco O (2), Viani GA (5), Rivera LML (1), Payão SLM $(1,4)$

(1) Sacred Heart University, Bauru, São Paulo State, Brazil; (2) Ourinhos Integrated College (FIO), Ourinhos, São Paulo State, Brazil; (3) Department of Morphology and Genetics, Federal University of São Paulo (Unifesp), São Paulo, São Paulo State, Brazil; (4) Department of Genetics, Famema Blood Center, Marília Medical School (Famema), Marília, São Paulo State, Brazil; (5) Department of Radiotherapy and Oncology, Marília Medical School (Famema), Marília, São Paulo State, Brazil.

\begin{abstract}
The risk of developing gastric cancer is believed to be related to differences among Helicobacter pylori strains and the inflammatory responses mediated by host genetic factors. H. pylori infection is acquired at an early age and in the absence of appropriate antibiotic therapy, it generally persists for life. Tp53 gene regulates the transcription of several cytokines and chemokines involved in innate immunity and its action may be influenced by the presence of different $H$. pylori strains. The present study aimed to detect $H$. pylori in pediatric patients, to access Tp53 polymorphism at codon 72 and to correlate such findings with age and histopathological results. Three hundred and forty-two patients were analyzed. DNA from their gastric biopsies was extracted and the detection of $H$. pylori was performed through polymerase chain reaction assays, urease test and histopathologic examination. Allelic discrimination of SNP rs1042522 (Tp53) was performed by real-time polymerase chain reaction. Our results suggest a possible relationship between the presence of $H$. pylori and chronic gastritis in children and young patients, and showed a significant association between ageing and positivity for $H$. pylori. It was verified that patients aged $\leq 10$ years were 1.3 times more likely to have infection by $H$. pylori when compared with those aged $>10$ years. Finally, no association was found between Tp53 polymorphisms and the presence of $H$. pylori.
\end{abstract}

Key words: Helicobacter pylori, childhood, Tp53 polymorphims, PCR.

\section{INTRODUCTION}

Helicobacter pylori is involved in the pathogenesis of a number of gastrointestinal diseases, including acute and chronic gastritis, peptic ulceration, gastric carcinoma and gastric lymphoma $(1,2)$. The risk of developing gastric cancer is believed to be related to differences among $H$. pylori strains and the inflammatory responses mediated by host genetic factors $(3,4)$.

Tp53 tumor suppressor gene has a common polymorphism at codon 72 , encoding either proline or arginine (P72 or R72, respectively) and a large number of epidemiological studies investigated the impact of this polymorphism on cancer risk. Frank et al. (5), suggest that there may be a minor association between the P72 allele and increased cancer risk. In addition, the transcription of the Tp53 gene is controlled by type I interferon signaling and the induction of Tp53 participates in the host defense against viral infection. Moreover, Tp53 regulates the transcription of several cytokines and chemokines involved in innate immunity and this can be influenced by the presence of different strains of H. pylori (5-7).

H. pylori infection is acquired at an early age (mostly before the age of 10), and in the absence of an antibiotic therapy, it generally persists for life (8). Studies have reported that the longer the 
time interval for $H$. pylori detection, the higher the risk of developing cancer $(9,10)$. Eradication should be performed at this time because once the gastric mucosa is irreversibly harmed, treatment does not prevent carcinogenesis $(8,11)$.

It is unclear if the gastric mucosa or oral cavity could be considered permanent or transient reservoirs for Helicobacter pylori. The results obtained in the present study established that the microhabitats of $H$. pylori are the gastric mucosa and oral cavity using the polymerase chain reaction (PCR) $(12,13)$.

Studies using DNA fingerprinting confirmed that members of the same family tend to be infected by the same strain of bacteria, a fact that confirms the interpersonal transmission, and should therefore be considered in addition to the socioeconomic conditions of the population $(8$, $14,15)$.

Other studies involving pediatric patients in developing countries show that the prevalence in children aged $\leq 10$ years is above $50 \%$. On de other hand, developed countries and those which have had an increase in their Human Development Index (HDI) show a reduction to around $10 \%$ in this age group $(9,16,17)$. These results highlight the importance of detecting $H$. pylori in childhood. Based on these findings, the present study was developed aiming at detecting the $H$. pylori in pediatric patients, genotype the Tp53 polymorphism at codon 72 and correlate with age and histopathological results.

\section{MATERIALS AND METHODS}

\section{Patients and Samples}

In this study, 342 dyspeptic patients (150 male and 192 female with a mean age 9.36 years) attended at Marília Medical School, Marília, SP, Brazil during the period between 2005 and 2011 were enrolled. All subjects were submitted to clinical examinations and only after previous medical indications they underwent endoscopic examination and investigation of peptic symptoms. All subjects had given their informed consent, and the study protocol was approved by the Ethics Committee of Sacred Heart University (n. 056/2005 and 223/2011).

Patients were divided into two groups according to their age. The first group included patients aged $\leq 10$ years and was composed of 193 patients (97 male and 96 female with a mean age 6.53 years \pm 2.67 ) and the second group was composed of 149 patients aged $>10$ years (53 male and 96 female with a mean age 12.94 years \pm 1.71$)$. During endoscopy, three gastric biopsy sections were taken from the antrum of each patient for detection of $H$. pylori. One was fixed in formalin, and assessed for the presence of $H$. pylori by histological examination, another section was used for rapid urease test and the third for molecular analysis.

\section{Detection of Helicobacter pylori}

DNA from the gastric biopsies was extracted with the QIAamp ${ }^{\varpi}$ tissue kit (Qiagen, Germany) according to the manufacturer's recommendations. Additional fresh biopsies were placed in rapid urease test, using the TUPF kit (Laborclin, Brazil), according to the manufacturer's instructions. After six hours, the TUPF test was inspected for a change in color. The samples from antrum for histopathologic examination were fixed in formalin and stained with hematoxylin and eosin (HE) and Giemsa. The histological features of the gastric mucosa were recorded using the updated Sydney scoring system (18).

Primers Hpx1 $\left({ }^{5}\right.$-CTGGAGARACTAAGYCCTCC- $\left.{ }^{3}\right)$ and Hpx 2 (5' GAGGAATACTCATTGCGAAGGCGA- ${ }^{3}$ ) targeting the $16 \mathrm{~S}$ ribosomal RNA gene of $H$. pylori were used according to the published data (13). PCR amplification was performed according to the method described previously $(12,13)$. In each experiment, positive (strain 26695) and negative (water) controls were included. The assay was considered positive when the PCR product was present.

\section{Genotyping of Tp53 Polymorphism}

Allelic discrimination of SNP rs 1042522 (Tp53) (assay id: c_2403545_10) was performed by real time polymerase chain reaction (RTPCR) on an Applied Biosystems 7500 Fast RealTime PCR system (Applied Biosystems ${ }^{\mathrm{Tw}}$, USA) using Taqman commercial probes (Applied Biosystems $^{\text {та }}$, USA). Genotyping of Tp53 followed the cycling program and conditions recommended by Applied Biosystems. The results were assessed taking into account the allelic discrimination and absolute quantitation in all samples; additionally, two negative controls per plate (non-template controls) were included. The interpretation was 
performed with software Taqman Genotyper v1.0 (Applied Biosystems ${ }^{\mathrm{Tn}}$, USA).

\section{Statistical Analyses}

Statistical analyses were performed by chisquare test and Fisher's test. The significance level was set at a $\mathrm{p}$ value of $<0.05$. Statistical analyses were performed using the statistical package SPSS 20.0 (Chicago, USA)

\section{RESULTS}

\section{Presence of $H$. pylori and Genotyping of Tp53 Gene}

H. pylori was detected in biopsies of the antrum in 85 out of $342(24.8 \%)$ patients by PCR assay. In addition, the histological analysis revealed the presence of $H$. pylori in 49 out of 286 subjects. Fifty-six patients did not have results by histological analysis and the urease test detected H. pylori infection in 68 out of $342(19.9 \%)$ patients.

In addition, examination of the histology of 286 biopsies found that 154 (53.8\%) patients had chronic gastritis, four (1.4\%) had esophagitis and $128(44.8 \%)$ patients had normal mucosa without gastric alterations. Forty-seven of 154 patients with chronic gastritis were $H$. pylori positive. On the other hand, only two of 128 patients without gastric alterations were $H$. pylori positive. This data may suggest a possible relationship between the presence of $H$. pylori and chronic gastritis in children and young patients.

No statistically significant difference was observed between gender and positivity for H. pylori $(\mathrm{p}<0.258)$. However, when age was compared with positivity for $H$. pylori an important association $(\mathrm{p}<0.026)$ was observed;

Table 1. Detection of Helicobacter pylori by PCR and its possible association with the age of patients

\begin{tabular}{c|c|c|c}
\hline \multirow{2}{*}{ PCR } & \multicolumn{2}{|c|}{ Age (years) } & \multirow{2}{*}{ Total } \\
\cline { 2 - 4 } & $\leq 10$ & $>10$ & $257(75.2 \%)$ \\
\hline H. pylori negative & $154(79.8 \%)$ & $103(69.2 \%)$ & $85(24.8 \%)$ \\
\hline H. pylori positive & $39(20.2 \%)$ & $46(30.8 \%)$ & $342(100 \%)$ \\
\hline Total & $* 193(100 \%)$ & $149(100 \%)$ & \\
\hline
\end{tabular}

$* p<0.026$

Table 2. Genotype distribution of Tp53 polymorphisms and H. pylori detection in childhood

\begin{tabular}{c|c|c|c|c}
\hline \multirow{2}{*}{ PCR } & \multicolumn{3}{|c|}{ Genotype } & Total \\
\cline { 2 - 5 } & CC & CG & GG & $257(75.2 \%)$ \\
\hline H. pylori negative & $120(75.5 \%)$ & $115(77.2 \%)$ & $22(64.7 \%)$ & $85(24.8 \%)$ \\
\hline H. pylori positive & $39(24.5 \%)$ & $34(22.8 \%)$ & $12(35.3 \%)$ & $342(100 \%)$ \\
\hline Total & $159(100 \%)$ & $149(100 \%)$ & $34(100 \%)$ & \\
\hline
\end{tabular}

the results showed that patients aged $\leq 10$ years were 1.3 times more likely to have PCR positive when compared with patients aged $>10$ years (Table 1).

We did not find any relation between Tp53 (rs1042522) polymorphisms and the presence of $H$. pylori. Genotype frequencies are presented in Table 2.

\section{DISCUSSION}

There are few studies involving pediatric patients in the literature investigating the detection of $H$. pylori in gastric biopsies and its association with age, route of transmission and Tp53 polymorphisms. The present study suggests a possible relationship between the presence of 
H. pylori and chronic gastritis in childhood. The analyses verified that 47 of 154 patients with chronic gastritis were $H$. pylori positive and only two of 128 patients without gastric alterations were $H$. pylori positive. These results are similar to those found by Gold (19), and Sherman et al. (20), thus suggesting an association between the presence of $H$. pylori and antral gastritis, and duodenal ulcers throughout childhood.

Pacifico et al. (17) in his review paper identifies, through a Medline search, studies published in English over the past two decades finding strong evidence of an association between $H$. pylori infection and antral gastritis and duodenal ulcer in children. The present study also shows a new and important relationship demonstrating that patients aged $<10$ years were 1.3 times more likely to test positive for $H$. pylori when compared with patients aged $>10$ years (Table 1 ). Goodman and Correa (21) suggest that early childhood is a high risk period for infection with $H$. pylori and the prevalence appears to increase rapidly until the early teen years. The forms of acquisition and transmission of $H$. pylori in children remains unclear. Fecal-oral, oral-oral, and gastro-oral routes have all been implicated in the transmission of the bacteria. Intra-familial clustering has been described in some studies (21-23)

Rothenbacher et al. (24), have suggested that mothers play a pivotal role in the transmission of $H$. pylori within a household. Nahar et al. (25) reported a strong relationship between $H$. pylori isolates from mothers and the young children, which suggests that transmission from mother to child occurs predominantly at a young age. Close and intimate contact between mother and, in particular, young children thus appears to be a key route responsible for the transmission of H. pylori. Possible behavioral risk factors for the transmission of $H$. pylori from mother to child may be the common use of spoons, sharing the teat of feeding bottles, and chewing or tasting of the child's food (25).

Sinha et al. (26) found $H$. pylori in maternal saliva and in the water in which soothers (pacifiers) were cleaned, which suggests possible routes of mother-to-child oral transmission. Kivi et al. (27) also state that the presence of infected family members is an important risk factor for children. These data suggest that a prophylactic treatment should be considered to all family members since the chronic colonization by $H$. pylori can influence the development of gastric tumors and diseases.

The role of $T p 53$ in innate immunity and the inflammatory response is now well established. Whereas the impact of the codon 72 polymorphism on cancer risk appears to be minor, there are compelling examples in the literature of an effect of this polymorphism on diseases associated with inflammation (5). In this study, it was not found an association of Tp53 (rs1042522) polymorphisms with the presence of $H$. pylori, similar results were found by Palli et al. (28), who verified no association between the presence of $T p 53$ mutations and various risk factors, including $H$. pylori infection, smoking habits, social class, education, and family history of gastric cancer.

Recently Jing et al. (29) suggested that the p53 codon 72 polymorphism modulates susceptibility to oral cancer in Chinese Han patients. On the other hand, Salehi and Hadavi (30) suggested that the TP53 codon 72 polymorphism do not confer susceptibility to prostate cancer in the Iranian population. The literature is controversial about association of presence of Tp53 mutations, risk factors and type of cancer. It is worth mentioning that the infection rates and $T p 53$ mutations can vary dramatically depending on the geographic region and race which may directly influence results.

In conclusion, no association was found between Tp53 polymorphisms and the presence of $H$. pylori. Moreover, no statistically significant difference was observed between gender and positivity for $H$. pylori. However, when comparing age with positive results for $H$. pylori, a significant association was observed and results showed that patients aged $\leq 10$ years were 1.3 times more likely to have positive PCR when compared with patients aged $>10$ years.

\section{ACKNOWLEDGMENTS}

The authors would like to thank The State of São Paulo Research Foundation (FAPESP), Sacred Heart University (USC) and Marília Medical School (FAMEMA).

\section{COPYRIGHT \\ (C) CEVAP 2012}




\section{SUBMISSION STATUS}

Received: February 10, 2012.

Accepted: August 23, 2012.

Abstract published online: September 3, 2012. Full paper published online: November 30, 2012.

\section{CONFLICTS OF INTEREST}

The authors declare no conflicts of interest.

\section{FINANCIAL SOURCE}

The State of São Paulo Research Foundation (FAPESP) provided the financial grants (project number 06/60836-1).

\section{ETHICS COMMITTEE APPROVAL}

The present study was approved by the Ethics Committee of Sacred Heart University, Bauru, SP, Brazil, under the following numbers: 056/2005 and $223 / 2011$.

\section{CORRESPONDENCE TO}

Spencer Luiz Marques Payão, Laboratório de Genética, Hemocentro, FAMEMA, Rua Lourival Freire, 240, Bairro Fragata, Marília, São Paulo, 17519-050, Brasil. Phone: +55 143402 1856. Fax: +55 143433 0148. Email: slmpayao@famema.br.

\section{REFERENCES}

1. Cameron EA, Powell KU, Baldwin L, Jones P, Bell GD, Williams SG. Helicobacter pylori: antibiotic resistance and eradication rates in Suffolk, UK, 1991-2001. J Med Microbiol. 2004;53(Pt 6):535-8.

2. Farshad S, Alborzi A, Japoni A, Ranjbar R, Hosseini Asl K, Badiee P, et al. Antimicrobial susceptibility of Helicobacter pylori strains isolated from patients in Shiraz, Southern Iran. World J Gastroenterol. 2010;16(45):5746-51.

3. Covacci A, Telford JL, Del Giudice G, Parsonnet J, Rappuoli R. Helicobacter pylori virulence and genetic geography. Science. 1999;284(5418):1328-33.

4. Assumpção MB, Martins LC, Melo Barbosa HP, Barile KA, de Almeida SS, Assumpção PP, et al. Helicobacter pylori in dental plaque and stomach of patients from Northern Brazil. World J Gastroenterol. 2010;16(24):3033-9.

5. Frank AK, Leu JI, Zhou Y, Devarajan K, Nedelko T, Klein-Szanto A, Hollstein M, et al. The codon 72 polymorphism of p53 regulates interaction with NF- $\{$ kappa $\}$ B and transactivation of genes involved in immunity and inflammation. Mol Cell Bbiol. 2011;31(6):1201-13.

6. Takaoka A, Hayakawa S, Yanai H, Stoiber D, Negishi $\mathrm{H}$, Kikuchi H, et al. Integration of interferon-alpha/ beta signalling to 53 responses in tumour suppression and antiviral defence. Nature. 2003;424(6948):516-23.

7. Muñoz-Fontela C, Macip S, Martínez-Sobrido L, Brown
L, Ashour J, García-Sastre A, et al.Transcriptional role of p53 in interferon-mediated antiviral immunity. J Exp Med. 2008;205(8):1929-38.

8. Buonavolontà $\mathrm{R}$, Miele $\mathrm{E}$, Russo $\mathrm{D}$, Vecchione $\mathrm{R}$, Staiano A. Helicobacter pylori chronic gastritis in children: to eradicate or not to eradicate? J Pediatr. 2011;159(1):50-6.

9. Blaser MJ, Chyou PH, Nomura A. Age at establishment of Helicobacter pylori infection and gastric carcinoma, gastric ulcer, and duodenal ulcer risk. Cancer Res. 1995;55(3):562-5.

10. Peek RM, Jr. Eradication of Helicobacter pylori as a means towards eliminating gastric adenocarcinoma. Gastroenterology. 2004;127(1):344-6.

11. Kikuchi S. Epidemiology of Helicobacter pylori and gastric cancer. Gastric Cancer. 2002;5(1):6-15.

12. Gatti LL, Fagundes e Souza EK, Leite KR, Bastos EL, Vicentini LR, Silva LC, et al. cagA vacA alelles and babA2 genotypes of Helicobacter pylori associated with gastric disease in Brazilian adult patients. Diagn Microbiol Infect Dis. 2005;51(4):231-5.

13. Rasmussen LT, Labio RW, Gatti LL, Silva LC, Queiroz VF, Smith MAC, et al. Helicobacter pylori detection in gastric biopsies, saliva and dental plaque of Brazilian dyspeptic patients. Mem Inst Oswaldo Cruz. 2010;105(3):326-30.

14. Kodaira MS, Escobar AM, Grisi S. Epidemiological aspects of Helicobacter pylori infection in childhood and adolescence. Rev Saude Publica. 2002;36(3):35669.

15. Drumm B, Rowland M. Why is Helicobacter pylori disappearing? More questions than answers. J Pediatr( Rio J). 2011;87(5):369-70.

16. Santos IS, Boccio J, Santos AS, Valle NC, Halal CS, Bachilli MC, et al. Prevalence of Helicobacter pylori infection and associated factors among adults in Southern Brazil: a population-based cross-sectional study. BMC Public Health. 2005;5:118.

17. Pacifico L, Anania C, Osborn JF, Ferraro F, Chiesa C. Consequences of Helicobacter pylori infection in children. World J Gastroenterol. 2010;16(41):5181-94.

18. Fonseca TL, Moraes EP, Juliano CR, Silva AM, Scaini CJ, Mendoza-Sassi RA, et al. Detection of Helicobacter pylori by phenotypic and genotypic methods. Dig M Dis Sci. 2010;55(6):1643-8.

19. Gold BD. Helicobacter pylori infection in children. Curr Probl Pediatr Health care. 2001;31(8):247-66.

20. Sherman P, Czinn S, Drumm B, Gottrand F, Kawakami E, Madrazo A, et al. Helicobacter pylori infection in children and adolescents: Working Group Report of the First World Congress of Pediatric Gastroenterology, Hepatology, and Nutrition. J Pediatr Gastroenterol Nutr. 2002;35(Suppl 2):S128-33.

21. Goodman KJ, Correa P. The transmission of Helicobacter pylori. A critical review of the evidence. Int J Epidemiol. 1995;24(5):875-87.

22. Goodman KJ, Correa P. Transmission of Helicobacter pylori among siblings. Lancet. 2000;355(9201):358-62.

23. Tindberg Y, Bengtsson C, Granath F, Blennow M, Nyrén O, Granström M. Helicobacter pylori infection in Swedish school children: lack of evidence of 
child-to-child transmission outside the family. Gastroenterology. 2001;121(2):310-6.

24. Rothenbacher D, Winkler M, Gonser T, Adler G, Brenner H. Role of infected parents in transmission of Helicobacter pylori to their children. Pediatr Infect Dis J. 2002;21(7):674-9.

25. Nahar S, Kibria KM, Hossain ME, Sultana J, Sarker SA, Engstrand L, et al. Evidence of intra-familial transmission of Helicobacter pylori by PCR-based RAPD fingerprinting in Bangladesh. Eur J Clin Microbiol Infect Dis. 2009;28(7):767-73.

26. Sinha SK, Martin B, Gold BD, Song Q, Sargent M, Bernstein CN. The incidence of Helicobacter pylori acquisition in children of a Canadian First Nations community and the potential for parent-to-child transmission. Helicobacter. 2004;9(1):59-68.
27. Kivi M, Johansson AL, Reilly M, Tindberg Y. Helicobacter pylori status in family members as risk factors for infection in children. Epidemiol Infect. 2005;133(4):645-52.

28. Palli D, Caporaso NE, Shiao YH, Saieva C, Amorosi A, Masala G, et al. Diet, Helicobacter pylori, and p53 mutations in gastric cancer: a molecular epidemiology study in Italy. Cancer Epidemiol Biomarkers Prev. 1997;6(12):1065-9.

29. Jing G, Lv K, Jiao X. The p53 Codon 72 Polymorphism and the Risk of Oral Cancer in a Chinese Han Population. Genet Test Mol Biomarkers. 2012.

30. Salehi Z, Hadavi M. Analysis of the codon 72 polymorphism of TP53 and human papillomavirus infection in Iranian patients with prostate cancer. J Med Virol. 2012;84(9):1423-7. 